\title{
Sikap masyarakat terhadap pengembangan Pantai Loang Baloq sebagai daya tarik wisata di Kota Mataram
}

\author{
M. Setyo Nugroho \\ Universitas Islam Negeri Mataram, Indonesia \\ Corresponding e-mail: tyonugroho@uinmataram.ac.id
}

\begin{abstract}
submitted: $\quad$ Purpose - This study aims to determine the community's attitude towards Aug-20, 2019 the development of Loang Baloq Beach in Mataram City.

accepted: $\quad$ Research method - Data were collected using observation techniques to Sep-28, 2019 Loang Baloq Beach, documentation studies in the form of documents related to Loang Baloq Beach, and distributing questionnaires to 100 people published: (accidental sampling) around Loang Baloq Beach, Mataram City.

Dec-02, 2019 Result - The result showed that the community agrees with the development of Loang Baloq Beach in the hope that it can become an economic locomotive and a place to promote Loang Baloq Beach at the international level. However, there are still some people who do not agree with the development of Loang Baloq Beach. This is because they think that tourism brings more harm than benefits.
\end{abstract}

Keywords: pengembangan pariwisata, pantai loang baloq, sikap masyarakat 


\section{PENDAHULUAN}

Pesona Kota Mataram menyimpan daya pikat pada keunikan budaya dan alam. Keunikan budaya tersaji dalam tradisi, adat, kuliner, dan gaya hidup masyarakatnya. Karya alam-NYA menciptakan bentangan alam yang begitu indah, sehingga dijadikan sebagai salah satu dari 11 Kawasan Strategis Pariwisata Daerah (KSPD). Daya tarik wisata yang ditetapkan pada KSPD memiliki 8 ruang lingkup pengembangan berdasarkan Rencana Induk Pembangunan Kepariwisataan Daerah (RIPPARDA) tahun 2013-2028, meliputi Kota Mataram, Islamic Center, Loang Baloq, Taman Mayura, Sekarbela, Taman Narmada, Suranadi, dan Lingsar ${ }^{1}$.

Masuknya Pantai Loang Baloq sebagai salah satu ruang lingkup pengembangan pariwisata di Kota Mataram menjadikan Pantai Loang Baloq sangat terbuka bagi investor untuk membangun fasilitas dan akomodasi di sana. Pemerintah sebagai sektor publik memiliki peran dan tanggung jawab dalam membangun kerangka operasional, dimana sektor publik dan privat terlibat dalam menggerakkan denyut nadi pariwisata. Artinya, pemerintah harus menerjemahkan kebijakan pariwisata yang disusun ke dalam rencana konkret terkait kerjasama dengan pihak swasta untuk pembangunan daya tarik wisata Pantai Loang Baloq.

Kendati demikian, idealnya pengembangan pariwisata harus melibatkan masyarakat sebagai elemen kunci di setiap destinasi wisata. Setiap sumber daya pariwisata, baik itu alam yang indah, eksotis kebudayaan dan kerafian lokal yang ada merupakan kekayaan yang dimiliki tuan rumah atau masyarakat yang mendiami suatu destinasi. Damanik dan Weber menambahkan bahwa masyarakat lokal merupakan pemilik langsung atraksi wisata yang dikunjungi sekaligus dikonsumsi wisatawan. Air, tanah, hutan dan lanskap serta kesenian yang menjadi salah satu daya tarik wisata juga hampir sepenuhnya milik mereka. Dengan demikian, perubahan-perubahan yang terjadi di daerah wisata akan bersentuhan langsung dengan kepentingan mereka² .

Pujaastawa menambahkan bahwa salah satu faktor yang sangat perlu mendapat perhatian dalam rangka penyusunan kebijakan pengembangan pariwisata adalah ada tidaknya kehendak bersama (common will) masyarakat untuk mengembangkan pariwisata setempat ${ }^{3}$. Sementara itu, pola pengembangan pariwisata selama ini masih bersifat top-down, artinya hegemoni kekuasaan masih sangat kuat, sehingga tidak jarang pengembangan pariwisata menimbulkan konflik kepentingan antara masyarakat dan pemerintah. Akhirnya masyarakat tiba pada posisi inferior dan hanya menjadi obyek semata dalam pembangunan pariwisata.

\footnotetext{
1 Peraturan Daerah Provinsi Nusa Tenggara Barat Nomor 7 Tahun 2013 Tentang Rencana Induk Pembangunan Kepariwisataan Daerah Tahun 2013-2018.

2 Janianton Damanik, Helmut F. Weber. Perencanaan Ekowisata: dari teori ke Aplikasi, (Yogyakarta: ANDI OFFSET. 2006), hlm 23.

3 Ida Bagus Gde Pujaastawa, dkk. 2005. Pariwisata Terpadu: Alternatif Model Pengembangan Pariwisata Bali tengah, (Bali: Universitas Udayana, Kampus Jimbaran, Kabupaten Badung. 2005), hlm 113.
} 
Berdasarkan pemaparan di atas, maka penelitian ini menjadi penting untuk melakukan survei sikap masyarakat terhadap pengembangan pariwisata di Pantai Loang Baloq sebagai daya tarik wisata di Kota Mataram sebagai ukuran untuk mengtetahui sejauh mana dukungan masyarakat untuk mengembangkan Pantai Loang Baloq sebagai daya tarik wisata di Kota Mataram.

\section{METODE PENELITIAN}

Metode penelitian ini menggunakan pendekatan kualitatif dan kuantitatif (mix method) dengan teknik pengumpulan data menggunakan observasi lapangan yakni pengamatan ke Pantai Loang Baloq di Kota Mataram. Kedua, yaitu studi pustaka berupa jurnal penelitian, dokumen yang berkaitan dengan Pantai Loang Baloq. Ketiga, yaitu menyebarkan kuesioner kepada 100 masyarakat (accidental sampling) di sekitar Pantai Loang Baloq. Salah satu alat yang digunakan untuk mengukur sikap suatu objek yang akan diteliti adalah menggunakan alat analisis skala likert. Skala ini dikembangkan oleh Rensis Likert untuk mengukur sikap masyarakat di tahun 1932. Salah satu aspek yang sangat penting guna mempelajari sikap dan prilaku manusia adalah masalah pengungkapan atau pengukuran sikap. Sugiyono menambahkan bahwa skala likert digunakan untuk mengukur sikap, pendapat, dan persepsi seseorang atau sekelompok orang tentang fenomena sosial. Dalam penelitian, fenomena sosial ini telah ditetapkan secara spesifik oleh peneliti, yang selanjutnya disebut sebagai variabel penelitian ${ }^{4}$.

Dalam penelitian ini, skala likert digunakan untuk mengukur sikap masyarakat terkait dukungan mereka terhadap pengembangan daya tarik wisata Pantai Loang Baloq di Kota Mataram. Berikut adalah skor penilaian menggunakan teknik skala likert, yaitu:

1. Sangat setuju, diberi skor 5

2. Setuju, diberi skor 4

3. Ragu-ragu, diberi skor 3

4. Tidak setuju, diberi skor 2

5. Sangat tidak setuju, diberi skor 1

Nilai rata-rata jawaban responden akan disesuaikan dengan rentang nilai skala likert pada Tabel 1. di bawah ini.

Tabel 1. Nilai Rata-Rata Skala Likert

\begin{tabular}{|l|l|l|l|}
\hline No & Sikap & Skor & Rentang \\
\hline 1 & Sangat Setuju & 5 & $4,21-5,0$ \\
\hline 2 & Setuju & 4 & $3,41-4,2$ \\
\hline
\end{tabular}

${ }^{4}$ Sugiyono. Metode Penelitian Kombinasi, (Bandung: Alfabeta. 2014). hlm 136. 
Sikap masyarakat terhadap pengembangan Pantai Loang Baloq... Journal of Enterprise and Development (JED), Vol. 1, No. 2, December 2019

\begin{tabular}{|l|l|l|l|}
\hline 3 & Ragu-ragu & 3 & $2,61-3,4$ \\
\hline 4 & Tidak setuju & 2 & $1,81-2,6$ \\
\hline 5 & Sangat tidak setuju & 1 & $1-1,8$ \\
\hline
\end{tabular}

sumber: Hasil Modifikasi Skala Likert

\section{HASIL DAN PEMBAHASAN}

Survei sikap masyarakat terhadap pengembangan daya tarik wisata Pantai Loang Baloq melalui penyebaran kuesioner kepada 100 masyarakat Kelurahan Tanjung Karang di Kota Mataram. Berikut distribusi penilaian sikap masyarakat disajikan pada Tabel 2. di bawah ini.

Tabel 2. Distribusi Penilaian Sikap Masyarakat terhadap Pengembangan Daya Tarik Wisata Pantai Loang Baloq di Kota Mataram

\begin{tabular}{|c|c|c|c|c|c|c|c|c|c|c|c|c|}
\hline \multirow{2}{*}{ Objek Sikap } & \multicolumn{2}{|c|}{$\begin{array}{l}\text { Sangat } \\
\text { Setuju }\end{array}$} & \multicolumn{2}{|c|}{ Setuju } & \multicolumn{2}{|c|}{ Ragu-Ragu } & \multicolumn{2}{|c|}{$\begin{array}{l}\text { Tidak } \\
\text { Setuju }\end{array}$} & \multicolumn{2}{|c|}{$\begin{array}{l}\text { Sangat } \\
\text { Tidak } \\
\text { Setuju }\end{array}$} & \multirow[b]{2}{*}{$\begin{array}{l}\text { Total } \\
\text { Skor }\end{array}$} & \multirow[b]{2}{*}{$\begin{array}{l}\text { Sikap } \\
\text { Masya } \\
\text { rakat }\end{array}$} \\
\hline & $\begin{array}{l}\text { Jml } \\
\text { (org } \\
\text { ) }\end{array}$ & Skor & $\begin{array}{l}\text { Jml } \\
\text { (org }\end{array}$ & Skor & $\begin{array}{l}\text { Jml } \\
\text { (org } \\
\text { ) }\end{array}$ & Skor & $\begin{array}{l}\text { Jml } \\
\text { (org }\end{array}$ & Skor & $\begin{array}{l}\text { Jml } \\
\text { (org } \\
\text { ) }\end{array}$ & Skor & & \\
\hline \begin{tabular}{lrr}
\multicolumn{2}{l}{ Pemilihan } & Lokasi \\
Pantai & Loang & Baloq \\
sebagai & Daya & Tarik \\
Wisata & di & Kota \\
Mataram. & & \\
& &
\end{tabular} & 45 & 225 & 30 & 120 & 8 & 24 & 7 & 14 & 10 & 10 & $\begin{array}{l}393 / \\
100 \\
=3,93\end{array}$ & Setuju \\
\hline $\begin{array}{lr}\text { Keinginan } & \text { untuk } \\
\text { Meningkatkan } & \text { Jumlah } \\
\text { Wisatawan di } & \text { Pantai } \\
\text { Loang Baloq. } & \end{array}$ & 57 & 285 & 24 & 96 & 8 & 24 & 2 & 4 & 9 & 9 & $\begin{array}{l}418 / \\
100 \\
=4,18\end{array}$ & Setuju \\
\hline $\begin{array}{lr}\text { Pengembangan } & \text { Daya } \\
\text { Tarik Wisata } & \text { Pantai } \\
\text { Loang Baloq } & \end{array}$ & 49 & 245 & 28 & 112 & 9 & 27 & 6 & 12 & 8 & 8 & $\begin{array}{l}404 / \\
100 \\
=4,04\end{array}$ & Setuju \\
\hline $\begin{array}{lr}\text { Keterlibatan } & \\
\text { Masyarakat } & \text { dalam } \\
\text { Pengembangan } & \text { Daya } \\
\text { Tarik Wisata } & \text { Pantai } \\
\text { Loang Baloq } & \end{array}$ & 49 & 245 & 34 & 136 & 4 & 12 & 4 & 8 & 9 & 9 & $\begin{array}{l}410 / \\
100 \\
=4,10\end{array}$ & Setuju \\
\hline $\begin{array}{l}\text { Pelatihan } \\
\text { Keterampilan } \\
\text { Pariwisata }\end{array}$ & 53 & 265 & 30 & 120 & 3 & 9 & 5 & 10 & 9 & 9 & $\begin{array}{l}413 / \\
100 \\
=4,13\end{array}$ & Setuju \\
\hline $\begin{array}{l}\text { Manfaat Ekonomi dari } \\
\text { Pengembangan Daya }\end{array}$ & 54 & 270 & 25 & 100 & 7 & 21 & 4 & 8 & 10 & 10 & $\begin{array}{l}409 / \\
100\end{array}$ & Setuju \\
\hline
\end{tabular}


Journal of Enterprise and Development (JED), Vol. 1, No. 2, December 2019

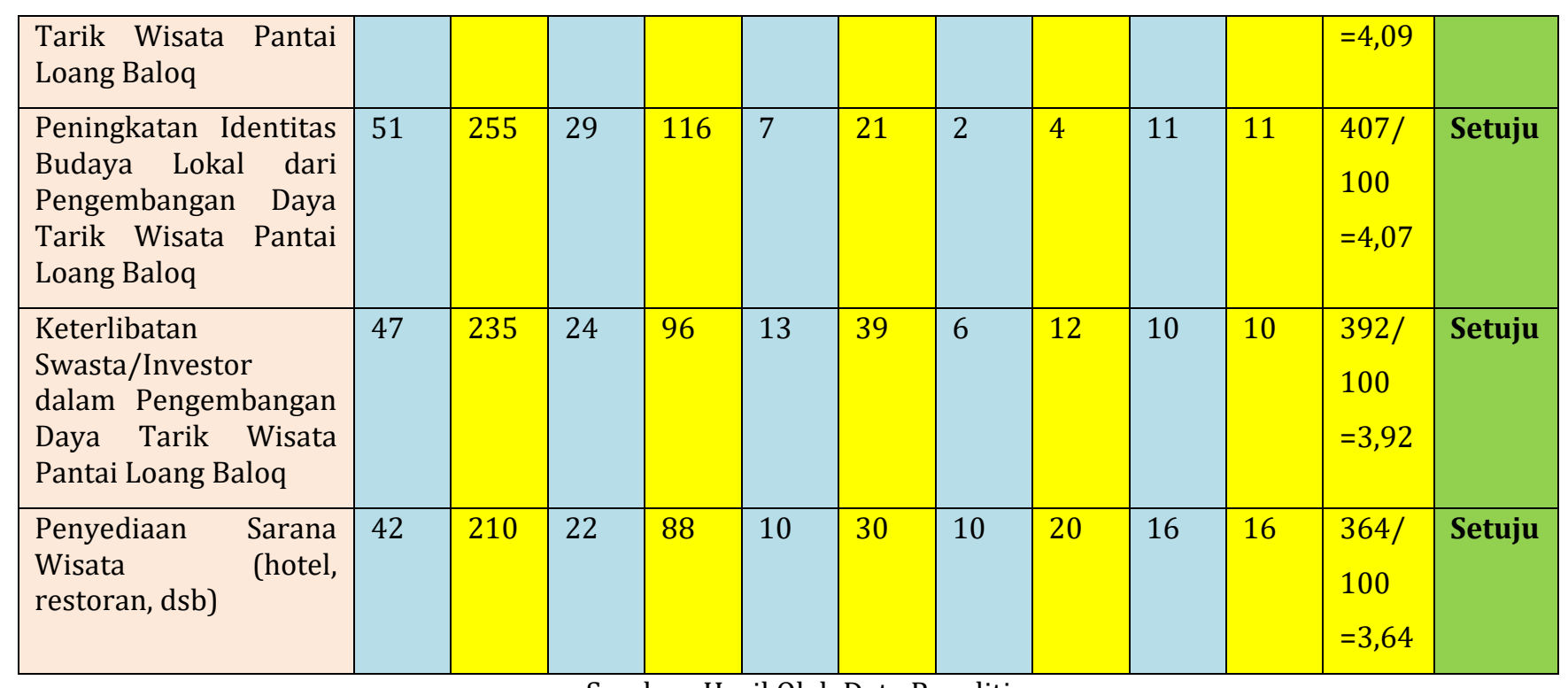

Sumber: Hasil Olah Data Peneliti

Keterangan:

Jml: Jumlah. Total Skor: $\frac{\text { Total Skor }}{\text { Jumlah Responden }}$

org: Orang.

\section{Sikap Masyarakat terhadap Lokasi Pantai Loang Baloq sebagai Daya Tarik Wisata di Kota Mataram}

Berdasarkan tabel 2 di atas, dapat dilihat total skor yang diperoleh sebesar 393 dengan rentang nilai 3,93. Artinya bahwa sikap masyarakat terhadap lokasi Pantai Loang Baloq sebagai daya tarik wisata di Kota Mataram menujukkan sikap setuju. Pantai Loang Baloq sebagai daya tarik wisata sangat sesuai dari segi atraksi wisata maupun akses lokasinya. Keindahan alam merupakan ciri khas yang dimiliki Pantai Loang Baloq karena memiliki pemandangan pantai yang membentang sekaligus sebagai tempat menyaksikan keindahan matahari terbenam (sunset). Selain itu, lokasi yang sangat strategis menjadikan Pantai Loang Baloq sangat mudah dijangkau oleh wisatawan. Hal tersebut dikarenakan Pantai Loang Baloq berada di Kota Mataram yang merupakan ibu kota provinsi Nusa Tenggara Barat (NTB). Berikut komentar masyarakat yang dituliskan pada lembar kuesioner yang diberikan:

"Karena tempatnya istimewa"5

"Karena letaknya strategis"6

${ }^{5}$ Dokumentasi Kuesioner oleh M. Sobirin, Selaku Masyarakat Kelurahan Tanjung Karang, Tanggal 2 Agustus 2017.

${ }^{6}$ Dokumentasi Kuesioner oleh Haruman, Selaku Masyarakat Kelurahan Tanjung Karang, Tanggal 2 Agusuts 2017. 


\section{Sikap Masyarakat terhadap Keinginan untuk Meningkatkan Jumlah Wisatawan di Pantai Loang Baloq.}

Berdasarkan tabel 2 di atas, dapat dilihat total skor yang diperoleh sebesar 418 dengan rentang nilai 4,18. Artinya bahwa sikap masyarakat terhadap keinginan untuk meningkatkan kunjungan wisatawan ke Pantai Loang Baloq menunjukkan sikap setuju. Hal tersebut dikarenakan potensi Pantai Loang Baloq yang begitu besar untuk dikembangkan, sehingga diharapkan nantinya dapat membuka lapangan pekerjaan sebanyak-banyaknya dan dapat meningkatkan kesejahteraan masyarakat sekitar. Pernyataan tersebut didukung oleh komentar responden yang menuliskan alasan pada kolom komentar kuesioner yang telah disebar seperti di bawah ini:

"Biar tambah maju dan dikenal banyak orang7"

"Supaya ada tambahan penghasilan dari lingkungan sekitar8"

Kendati demikian, penting untuk diperhatikan batasan (limit), batas atas (ceiling) yang tidak boleh dilewati dalam pengembangan destinasi pariwisata. Oleh sebab itu, jumlah kunjungan wisatawan harus sesuai dengan daya dukung (carriying capacity) agar dapat menjaga kondisi fisik, lingkungan dan sosial komunitas lokal di Pantai Loang Baloq.

\section{Sikap Masyarakat terhadap Pengembangan Daya Tarik Wisata Pantai Loang Baloq}

Berdasarkan tabel 2 di atas, dapat dilihat total skor yang diperoleh sebesar 404 dengan rentang skor sebesar 4,04. Artinya masyarakat menunjukkan sikap setuju terhadap pengembangan daya tarik wisata Pantai Loang Baloq. Komitmen masyarakat dalam membangun destinasi merupakan kunci utama dalam proses penyusunan kebijakan nantinya. Hal tersebut dikarenakan masyarakat adalah subjek yang akan terlibat langsung, bahkan sejak tahap awal perencanaan hingga tahap pengambilan keputusan. Selain itu, beberapa responden juga menuliskan alasannya mendukung pengembangan Pantai Loang Baloq sebagai berikut:

"Agar masyarakat lebih peduli dan lebih menjaga serta ikut serta melestarikannya ${ }^{9 "}$

"Karena kalau tidak ada dukungan dari masyarakat, pariwisata Loang Baloq tidak akan berkembang dengan baik ${ }^{10 "}$

\footnotetext{
${ }^{7}$ Dokumentasi Kuesioner oleh Lalu Abdul, Selaku Masyarakat Kelurahan Tanjung Karang, Tanggal 9 Agustus 2017.

${ }^{8}$ Dokumentas Kuesioner oleh Suliyanto, Selaku Masyarakat Kelurahan Tanjung Karang, Tanggal 2 Agustus 2017

${ }^{9}$ Dokumentasi Kuesioner oleh M. Romzi. Selaku Masyarakat Kelurahan Tanjung Karang. Tanggal 4 Agustus 2017.

${ }^{10}$ Dokumentasi Kuesionerl oleh Adinda. Selaku Masyarakat Kelurahan Tanjung Karang. Tanggal 2 Agustus 2017).
} 
Pantai Loang Baloq memiki potensi fisik yang sangat menarik. Menurut penelitian yang dilakukan Nugroho mengatakan bahwa Pantai Loang Baloq memiliki potensi produk wisata yang terbagi menjadi 3 area, pertama yaitu area darat pantai yang meliputi sightseeing, sunset point, sport seperti bola dan voli pantai, outbond dan camping. Kedua, yaitu area laut meliputi aktivitas berenang, water sport seperti banana boat, kano dan fishing area. Ketiga, yaitu area muara yaitu muara yang dapat dikelilingi menggunakan perahu bebek yang disewakan oleh pihak pengelola. ${ }^{11}$

\section{Sikap Masyarakat terhadap Keterlibatan Masyarakat dalam Pengembangan Daya Tarik Wisata Pantai Loang Baloq}

Berdasarkan tabel 2 di atas, dapat diketahui bahwa total skor yang diperoleh sebesar 410 dengan rentang skor sebesar 4,10. Artinya masyarakat menunjukkan sikap setuju untuk terlibat dalam pengembangan Pantai Loang Baloq. Bentuk partisipasi masyarakat terbagi menjadi langsung dan tidak langsung. Paritisipasi langsung masyarakat di Pantai Loang Baloq terlihat dari beberapa masyarakat yang bekerja sebagai anggota pengelola atau pengurus pantai, pengelola jasa restoran, pedagang kuliner dan souvenir hasil kerajinan tangan. Sedangkan bentuk partisipasi tidak langsung terlihat dari beberapa masyarakat sebagai supplier bahan kebutuhan proyek wisata seperti bahan pangan (beras, sayur, minuman, ikan hasil tangkapan nelayan sekitar).

Masyarakat sebagai detak jantung dari kegiatan pariwisata di Pantai Loang Baloq sudah menunjukkan semangat kepedulian mereka terhadap pentingnya menjaga dan melestarikan potensi pariwisata setempat, sehingga dapat menjamin kegiatan pariwisata berjalan dengan baik dan memberikan manfaat bagi masyarakat sekitar. Hal tersebut terlihat melalui pendapat responden yang menuliskan alasan pada kolom komentar kuesioner yang telah disebar sebagai berikut:

"Agar masyarakat lebih peduli dan lebih menjaga serta ikut serta melestarikannya"12

"Karena ingin menjadi bagian pengurus Loang Baloq"13

"Karena kalau tidak ada dukungan dari masyarakat, pariwisata Loang Baloq tidak akan berkembang dengan baik"14

\footnotetext{
${ }^{11}$ M. Setyo Nugroho. "Identifikasi Komponen Pendukung Daya Tarik Wisata Loang Baoq Sebagai Wisata Pesisir Di Kota Mataram". Media Bina Ilmiah. Vol.13, No.9, 2019, hlm 1621-1622.

12 Dokumentasi Kuesinoer oleh M. Romzi. Selaku Masyarakat Kelurahan Tanjung Karang, Tanggal 4 Agustus 2017,

${ }^{13}$ Dokumentasi Kuesioner oleh Mardiansyah Ali Saputra. Selaku Masyarakat Kelurahan Tanjung Karang. Tanggal 3 Agustus 2017),

${ }^{14}$ Dokumentasi Kuesioner oleh Adinda. Selaku Masyarakat Kelurahan Tanjung Karang. Tanggal 2 Agustus 2017.
} 


\section{Sikap Masyarakat terhadap Pelatihan Keterampilan Pariwisata}

Berdasarkan tabel 2 di atas, dapat diketahui bahwa total skor yang diperoleh sebesar 413 dengan rentang skor sebesar 4,13. Artinya masyarakat menunjukkan sikap setuju untuk mendapat pelatihan-pelatihan untuk membangun keterampilan seperti pemandu wisata, bahasa asing dll. Pelatihan keterampilan pariwisata menjadi salah faktor penting untuk meningkatkan kualitas destinasi. Pitana dan Diarta menyatakan bahwa sebagai salah satu industri jasa, sikap dan kemampuan staff akan berdampak krusial terhadap bagaimana pelayanan pariwisata diberikan kepada wisatawan yang secara langsung akan berdampak pada kenyamanan, kepuasan dan kesan atas kegiatan wisata yang dilakukannya ${ }^{15}$. Adapun alasan yang dikemukakan oleh masyarakat seperti berikut:

"Menambah pengalaman/keterampilan biar tidak dikuasai oleh orang luar"16

"Supaya tambah wawasan dan pengalaman"17

\section{Sikap Masyarakat terhadap Manfaat Ekonomi dari Pengembangan Daya Tarik Wisata Pantai Loang Baloq}

Berdasarkan tabel 2 di atas, dapat diketahui bahwa total skor yang diperoleh sebesar 409 dengan rentang skor sebesar 4,09. Artinya masyarakat setuju bahwa melalui pengembangan pariwisata Pantai Loang Baloq dapat meningkatkan lapangan kerja dan pendapatan masyarakat sekitar. Hal tersebut juga diakui oleh masyarakat yang menulis alasan pada kolom komentar kuesioner sebagai berikut:

"Karena sejauh ini menambah penghasilan masyarakat sekitar"18

"Menambah mata pencaharian"19

\section{Sikap Masyarakat terhadap Peningkatan Identitas Budaya Lokal dari Pengembangan Daya Tarik Wisata Pantai Loang Baloq}

Berdasarkan tabel 2 di atas, dapat diketahui bahwa total skor yang diperoleh sebesar 407 dengan rentang skor sebesar 4,07. Artinya masyarakat setuju bahwa

\footnotetext{
${ }^{15}$ I Gde Pitana dan I Ketut Surya Diarta. Pengantar Ilmu Pariwisata. (Yogyakarta: Andi Offset 2009). hlm 72.

${ }^{16}$ Dokumentasi Kuesioner oleh Aan. Selaku Masyarakat Kelurahan Tanjung Karang. Tanggal 5 Agustus 2017.

${ }^{17}$ Dokumentasi Kuesioner oleh Suliyanto. Selaku Masyarakat Kelurahan Tanjung Karang. Tanggal 2 Agustus 201

${ }^{18}$ Dokumentasi Kuesioner oleh M. Romzi. Selaku Masyarakat Kelurahan Tanjung Karangf, karyawan, Tanggal 4 Agustus 2017.

${ }^{19}$ Dokumentasi Kuesioner oleh Miskiah. Selaku Masyarakat Kelurahan Tanjung Karang. Tanggal 4 Agustus 2017.
} 
pengembangan pariwisata Pantai Loang Baloq dapat meningkatkan identitas budaya lokal. Sejauh ini, masyarakat sekitar masih mempertahankan identitas lokal suku Sasak Pulau Lombok yang kental dengan adat, tradisi dan kearifan lokal yang ada. Lombok dalam bahasa Sasak berarti lurus, artinya memiliki hati dan jiwa yang lurus ${ }^{20}$. Lebih lanjut masyarakat Loang Baloq aktif dalam organisasi keagamaan seperti "Remaja Masjid atau Remaja Mushola". Hal tersebut salah satu contoh budaya masyarakat lokal yang masih ditemukan di era perkembangan pariwisata di Pulau Lombok secara umum, dan Loang Baloq secara khusus.

Di Pantai Loang Baloq, banyak kebudayaan lokal yang menjadi daya tarik bagi wisatawan, seperti tradisi Nyongkolan, Presean, dan seni tari. Tradisi budaya yang ada harus senantiasa dilestarikan agar keberadaanya tidak terkikis globalisasi dan semakin diminati oleh wisatawan, oleh sebab itu, mayoritas masyarakat menyatakan setuju bahwa pengembangan daya tarik wisata Pantai Loang Baloq dapat meningkatkan identitas budaya lokal. Hal tersebut dinyatakan oleh responden yang menuliskan alasan:

"ramai diminati orang banyak"21

\section{Sikap Masyarakat terhadap Keterlibatan Swasta/Investor dalam Pengembangan Daya Tarik Wisata Pantai Loang Baloq}

Berdasarkan tabel 2 di atas, dapat diketahui bahwa total skor yang diperoleh sebesar 392 dengan rentang skor sebesar 3,92. Artinya masyarakat setuju untuk bekerja-sama dengan pihak pemilik modal. Sikap setuju masyarakat juga didasarkan bentuk kepedulian mereka supaya Pantai Loang Baloq dapat lebih dikenal di mata dunia dan senantiasa meningkatkan promosi. Hal tersebut dinyatakan oleh responden yang menuliskan alasan:

"Harus bisa jadi nomor 1 "22

"akan lebih terkenal di luar negeri"23

Sektor privat diartikan sebagai sektor yang berada diluar dari pemerintah seperti perusahaan, pebisnis dan pengusaha. Sektor ini mempunyai peranan vital dalam perencanaan pariwisata karena tersedianya akomodasi pada suatu destinasi wisata (hotel, travel agent, $\mathrm{dsb}$ ) berasal atau digerakkan oleh sektor privat. Kendati demikan, pengembangan pariwisata tidak bisa diserahkan sepenuhnya kepada swasta, melainkan dibutuhkan kerjasama kolaboratif antara

\footnotetext{
${ }^{20}$ M. Setyo Nugroho. “Identifikasi Komponen Pendukung ......... hlm 1623.

${ }^{21}$ Dokumentasi Kuesioner oleh Abdul Warok. Selaku Masyarakat Kelurahan Tanjung Karang. Tanggal 3 Agustus 2017.

${ }^{22}$ Dokumentasi Kuesioner oleh Angger. Selaku Masyarakat Kelurahan Tanjung Karang. Tanggal 3 Agustus 2017.

${ }^{23}$ Dokumentasi Kuesioner oleh M. Isnaini. Selaku Masyarakat Keluragan Tanjung Karang. 4 Agustus 2017.
} 
seluruh stakeholder yang sifatnya simbiosis mutualisme, dan hendaknya mencari investor yang pro terhadap green tourism, sehingga pengembangan tersebut tidak bersifat oportunis dan jangka pendek, melainkan jangka panjang dan berlanjut seperti halnya konsep pariwisata berkelanjutan secara ekonomi, ekologi, dan sosial budaya ${ }^{24}$.

\section{Sikap Masyarakat terhadap Penyediaan Sarana Wisata (hotel, restoran, dsb)}

Berdasarkan tabel 2 di atas, dapat diketahui bahwa total skor yang diperoleh sebesar 364 dengan rentang skor sebesar 3,64. Artinya masyarakat setuju untuk menambah kualitas maupun kuantitas sarana wisata di Pantai Loang Baloq seperti hotel, restoran dan lain sebagainya. Sikap masyarakat tersebut didasari pada aspek pelayanan kepada wisatawan dan harapan untuk mendapat pekerjaan. Hal tersebut dinyatakan oleh responden yang menuliskan alasan:

"supaya wisatawan merasa puas" 25

"supaya ada tempat bekerja"26

Jackson mengatakan bahwa suatu destinasi harus menyediakan berbagai kebutuhan yang diperlukan wisatawan, agar tujuan kunjungan seorang wisatawan dapat terpenuhi. Terdapat empat elemen utama untuk mencapai tujuan umum dan khusus dari wisatawan, yaitu facilities, accommodation, transportation dan attraction ${ }^{27}$. Kendati demikian, fasilitas bukanlah segalanya, melainkan hanya pelengkap bagi suatu destinasi. Hal tersebut dikarenakan motivasi perjalanan wisatawan yang beragam. Plog membagi tipologi menjadi 2 bagian yakni allocentric dan psychocentric. Allocentric adalah wisatawan yang mengunjungi tempat yang belum diketahui dan memanfaatkan fasilitas seadanya, sedangkan psychocentric adalah wisatawan yang hanya ingin mengunjungi daerah wisata yang sudah mempunyai fasilitas dengan standar yang sama dengan di negara asalnya ${ }^{28}$. Sementara itu, paradigma yang berkembang saat ini adalah terjadinya perubahan pada pola perjalanan wisatawan yang dulunya bersifat leisure oriented menjadi experience oriented. Artinya wisatawan tidak lagi mencari hotel dan fasilitas mewah, melainkan lebih mengutamakan pengalaman perjalanan mereka. Oleh karena itu, otensitas daya tarik wisata akan menjadi pemicu terjadinya perjalanan wisata.

\footnotetext{
${ }^{24}$ M. Setyo Nugroho. Eksplorasi Potensi Pulau Lombok Sebagai Destinasi Wisata Halal di Nusa Tenggara Barat. Media Bina IImiah. Vol.13, No.7, 2018. HIm 1342.

${ }^{25}$ Dokumentasi Kuesioner oleh M. Sobirin. Selaku Masyarakat Kelurahan Tanjung Karang. Tanggal 9 Agustus 2017

${ }^{26}$ Dokumentasi Kuesioner oleh Suliyanto. Selaku Masyarakat Kelurahan Tanjung Karang. Tanggal 2 Agustus 2017

${ }^{27}$ Ian Jackson. An Introduction to Tourism. (Melbourne:Hospitality Press.1989).

${ }^{28}$ Plog, S. Why Destination Areas Rise and Fall in Popularity. Cornell Hotel and Restaurant Administration Quarterly, Vol.12, 1973. HIm 13-16.
} 


\section{KESIMPULAN}

Mayoritas masyarakat di Pantai Loang Baloq sangat mendukung pengembangan Daya Tarik Wisata Pantai Loang Baloq di Kota Mataram. Hal tersebut terlihat dari sikap masyarakat yang menyetujui pengembangan Pantai Loang Baloq dengan tujuan meningkatkan pendapatan dan mensejahterakan masyarakat, serta menjadi pendorong untuk senantiasa melestarikan tradisi budaya masyarakat setempat. Oleh sebab itu masyarakat ingin berpastisipasi dan senantiasa dilibatkan dalam pengembangan Pantai Loang Baloq. Dengan demikian, masyarakat Kelurahan Tanjung Karang ingin pemerintah terus membangun infrastruktur, sarana dan fasilitas wisata serta melakukan kerjasama dengan seluruh stakeholder dalam membangun daya tarik wisata Pantai Loang Baloq.

Masyarakat merupakan elemen kunci dari suatu destinasi, sehingga dibutuhkan komitmen kuat dari masyarakat dalam berpatisipasi dalam pengembangan daya tarik wisata Pantai Loang Baloq, sehingga pengembangan tersebut tidak bersifat oportunis dan jangka pendek, melainkan jangka panjang dan berlanjut seperti halnya konsep pariwisata berkelanjutan secara ekonomi, ekologi, dan sosial budaya. 
Journal of Enterprise and Development (JED), Vol. 1, No. 2, December 2019

\section{DAFTAR PUSTAKA}

Ahmadi, A. 2007. Psikologi Sosial. Jakarta: Rineka Cipta.

Azwar, S. 2005. Sikap Manusia, Teori dan Pengukuranya. Yogyakarta: Pustaka Pelajar.

Damanik, J. Weber, Helmut, F. 2006. Perencanaan Ekowisata: dari teori ke Aplikasi. Yogyakarta. ANDI OFFSET.

Jackson, Ian. 1989. An Introduction to Tourism. Melbourne:Hospitality Press

Nugroho, M. Setyo. 2018. Eksplorasi Potensi Pulau Lombok Sebagai Destinasi Wisata Halal di Nusa Tenggara Barat. Media Bina Ilmiah. Vol.13, No.7, hal 1337-1342.

Nugroho, M. Setyo. 2019. Identifikasi Komponen Pendukung Daya Tarik Wisata Loang Baoq Sebagai Wisata Pesisir Di Kota Mataram. Media Bina Ilmiah. Vol.13, No.9, hal 1619-1626.

Pitana, I. G. dan Diarta, I. K. S. 2009. Pengantar Ilmu Pariwisata, Yogyakarta: Andi Offset.

Plog, S. 1973. Why Destination Areas Rise and Fall in Popularity. Cornell Hotel and Restaurant Administration Quarterly. Vol 12, Hal 13-16.

Pujaastawa, I.B.G, Wirawan, I.G.P dan Adhika, I Made. 2005. Pariwisata Terpadu: Alternatif Model Pengembangan Pariwisata Bali tengah. Bali: Universitas Udayana, Kampus Jimbaran, Kabupaten Badung.

Sugiyono, 2014, Metode Penelitian Kombinasi. Bandung: Alfabeta. 